\title{
Phytosociology and plant community utilisation by vervet monkeys of the Blydeberg Conservancy, Limpopo Province
}

\author{
A.S. Barrett, L.R. Brown, L. Barrett and S.P. HenzI
}

Barrett, A.S., L.R. Brown, L. Barrett and S.P. Henzi. 2006. Phytosociology and plant community utilisation by vervet monkeys of the Blydeberg Conservancy, Limpopo Province. Koedoe 49(1): 49-68. Pretoria. ISSN 0075-6458.

The plant communities of the Blydeberg Conservancy were investigated as part of a research project on the foraging ecology of vervet monkeys Cercopithecus aethiops pygerythrus (senso lato) in mixed lowveld bushveld and sour lowveld bushveld areas. To date there are no formal management plans for vervet monkeys. This is attributed to the limited knowledge of vervets and their utilisation of and impacts on ecosystems. From a TWINSPAN classification refined by Braun-Blanquet procedures, ten plant communities that can be placed into four major groups were identified. A classification and description of these communities, including a vegetation map are presented. Diagnostic species as well as prominent and less conspicuous species of tree, shrub, herb and grass strata are outlined. Of the ten available plant communities, the vervets utilised only six during the study period. There was an abundant supply of various food sources throughout the year, with movement patterns mostly coinciding with the fruiting times of several tree and other plant species.

Keywords: Braun-Blanquet procedures, conservancy, plant communities, TWINSPAN, vervet monkeys.

\begin{abstract}
A.S. Barrett and L.R. Brown, Applied Behavioural Ecology and Ecosystem Research Unit, University of South Africa, Florida Campus, RSA; L. Barrett and S.P. Henzi, Applied Behavioural Ecology and Ecosystem Research Unit, University of South Africa, Florida Campus, RSA (Present address: Department of Psychology, University of Central Lancashire, Lancashire, UK)
\end{abstract}

\section{Introduction}

The Blydeberg Conservancy constitutes a group of privately owned farms belonging to individuals with varying interests. Owners have diverse backgrounds including farming, hunting, research, business and property development. The intention of the conservancy was to pool resources and properties to form a large area containing various game species for tourism ventures and private utilisation.

Not many extensive vegetation studies have been carried out in the Blydeberg area or surrounds and those that have been completed (Van der Schijff 1963; Van der Schijff \& Schoonraad 1971), were done only once, without any recorded follow-up surveys. Due to the various land-use practices occurring within the area and their long-term effects on ecosystems, as well as the research project on vervet monkeys Cercopithecus aethiops pygerythrus (senso lato) undertaken in the area (Barrett 2005), it was deemed important to undertake a vegetation description and classification of the Blydeberg Conservancy.

It is widely recognised that a detailed description, identification, classification and mapping of vegetation forms the basis of sound land-use planning and management (Tueller 1988; Fuls et al. 1992; Fuls 1993; Bezuidenhout 1996; Brown 1997). The results obtained from this study could therefore be used to assist management in making decisions for the conservancy, whilst simultaneously providing data for the determination of the seasonal foraging ecology of vervet monkeys. The main aim of this study thus was to describe and map the plant communities of the study area within the Blyde- 
berg Conservancy in order to determine the seasonal foraging ecology of a troop of vervet monkeys living within the area. Vegetation assessments are prerequisites to any ecological or habitat related research, forming a basis to any further studies.

Vervets are extremely adaptable opportunistic generalists (similar to baboons but, less so) that easily move into disturbed areas, including agricultural areas and lodges. They can even be found in specialised habitats such as mangrove swamps (Oates 1996; Kingdon 1997; Fedigan \& Fedigan 1988; Skinner \& Smithers 1990; Booth 1979). Vervets are capable of becoming a pest species in areas where they are forced into close proximity with humans, leading to conflict and ultimately their demise. The aim of the encompassing study on vervet foraging ecology is to elucidate some of their foraging behaviour. It is anticipated that results obtained from such a study would assist management in successfully implementing management plans for vervets. Not many detailed ecological studies of vervets have been undertaken in temperate subtropical areas (Struhsaker 1967; Harrison 1983, 1984; Whitten 1988; Lee \& Hauser 1998; Isbell et al. 1998; Pruetz \& Isbell 2000). At these low latitudes, overall habitat productivity is high and seasonal variability is relatively constrained (Caughley \& Sinclair 1994). A fuller understanding of vervet ecological flexibility, as well as the factors that might limit their distribution both broadly and locally, is likely to be derived from this study and will benefit the overall management of the species. No related vervet studies have been undertaken locally; however, a study on baboon resource utilisation has been done in the Blyde Canyon Nature Reserve (Marais 2005), though they mostly feed at different strata.

\section{Study Area}

The Blydeberg Conservancy is situated approximately $19 \mathrm{~km}$ south of the town of Hoedspruit in the Limpopo Province (Fig. 1). It is located between longitude $30^{\circ} 27^{\prime} \mathrm{E}-25^{\circ} 56^{\prime} \mathrm{E}$ and latitude $24^{\circ} 23^{\prime} \mathrm{S}-$ $24^{\circ} 28^{\prime} \mathrm{S}$. Altitude ranges from $350-800 \mathrm{~m}$ above sea level (Low \& Rebelo 1998). The study area constitutes the farms Dunstable (farm number 230) and Jongmanspruit (farm number 234). The current size of the Blydeberg Conservancy is 3000 ha with the study area being 816 ha.

The geology of the conservancy ranges from a zone of fine to medium-grained quartzite, gritty in places, with pebble layers; basic lava, tuff, agglomerate and shale in the south; to a zone of light-grey, mediumgrained biolite gneiss with coarse-grained quartz-feldspar leucosomes, recrystallised in places in the north (Visser 1989; Walraven 1989). An intermediate zone of laminated micaceous and graphitic shale, locally interlayered with sandy shale, flagstone and quartzite seperates the southern and northern zones (Visser 1989; Walraven 1989). Also, according to Visser (1989) and Walraven (1989), intermittently layered along the south of the northern zone and between such and the intermediate zone is another less distinct zone of greenish grey intermediate lava, amygdaloidal in places, interbedded porphyritic layers and layers of shale and quartzite. Visser (1989) and Walraven (1989), state that the southern, intermediate and the less distinct zone between the northern and intermediate zones are rocks of volcanic and sedimentary origin dating back to the Vaalian Quaternary. The southern zone originates from the Black Reef Formation of the Transvaal Sequence; the intermediate zone originates from the Selati Formation of the undifferentiated upper part of the Wolkberg Group and the less distinct zone between the northern and intermediate zones originates from the Abel Erasmus Formation of the undifferentiated lower part of the Wolkberg Group (Visser 1989; Walraven 1989; Buckle 1992). The northern zone is rock of intrusive origin, dating back to the Swazian Quaternary (Visser 1989; Walraven 1989; Buckle 1992).

The topography is mostly mountainous with steep to moderately steep slopes gradually tapering off to a relatively flat mountain 


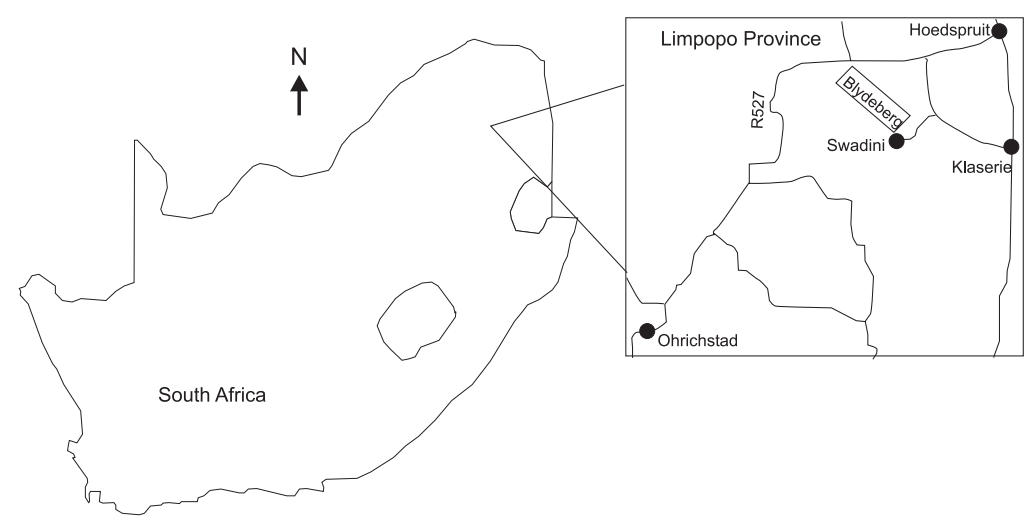

Fig. 1. Location of Blydeberg Conservancy within the Limpopo Province of South Africa.

plateau. Patches of montane forest occur at higher altitudes in kloofs and ravines. Due to dense shade caused by an almost continuous tree canopy, very little ground cover is present in the forest patches, however many ferns and lianas including Dalbergia armata, Capparis tomentosa, Strophanthus speciosus and Hippocratea crenata prevail. Larger canopy trees found in such patches include Celtis africana, Rauvolfia caffra, Trichilia dregeana, Nuxia oppositifolia and Ficus sycomorus.

The vegetation comprises a mixture of dense montane forest in kloofs; open tree savanna/sour bushveld on northern and western slopes; and high mountain sour grass veld and dense riverine thickets along drainage lines and streams. The area is rather patchy and vegetation varies from relatively open bushveld with long grass species on undulating hills and slopes, through dense shrub and scrub in dry ravines and dongas, to patches of semi-montane forest in sheltered kloofs. According to Low \& Rebelo (1998), the area can be classified as intermediate between Mixed Lowveld Bushveld (veld type 19) and Sour Lowveld Bushveld (veld type 21).

Four land types, namely $\mathrm{Fa}, \mathrm{Fb}, \mathrm{Ib}$ and $\mathrm{Ic}$, occur in the study area. According to Land Type Survey Staff (1989), “A land type denotes an area that can be shown at 1:250000 scale and displays a marked degree of uniformity with respect to terrain form, soil pattern and climate".

The $\mathrm{F}$ land type refers to pedologically young landscapes that are not predominantly rock and alluvial or aerolian in which the main soil forming processes have been rock weathering (Land Type Survey Staff 1989). Dominant soil forms are Glenrosa and Mispah. However, exposed rock and soils belonging to almost any of the other 39 soil forms may occur in type $\mathrm{F}$ land types. Both shallow and deep soils of the Oakleaf form are present in upland areas.

In the Fa land type lime in the soil is not commonly encountered and is rare or absent throughout the landscape. This land type consists of two terrain units, mid slopes comprising $95 \%$ of the land type, and valley bottoms constituting the remaining $5 \%$ of the land type. Soils are mostly medium sandy loam to sandy clay loam and are shallower than $400 \mathrm{~mm}$ (Land Type Survey Staff 1989).

In the $\mathrm{Fb}$ land type, lime in the soil is rare or absent in upland areas but, generally, lime is present in low-lying areas. This land type consists of two terrain units, footslopes com- 


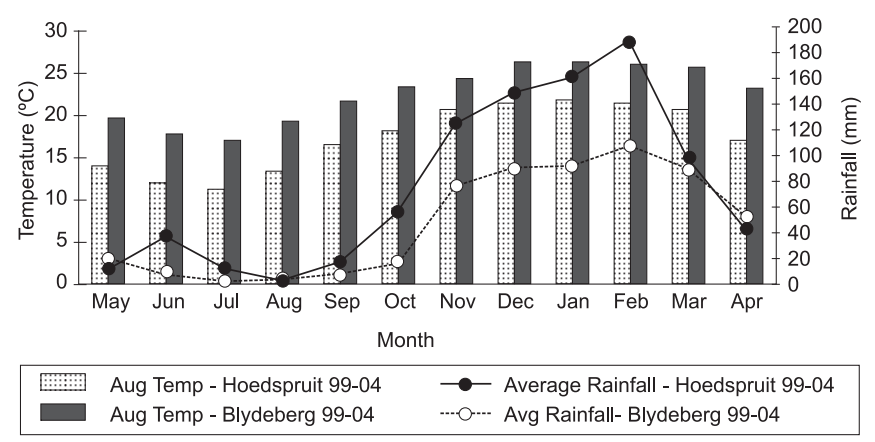

Fig. 2. Average monthly rainfall and temperatures for the Blydeberg Conservancy and Hoedspruit from 05/1999 to 04/2004.

prising $80 \%$ of the land type, and valley bottoms constituting $20 \%$ of the land type. Soils are mostly medium to coarse sand to loamy sand and shallower than $1200 \mathrm{~mm}$ (Land Type Survey Staff 1989).

The land type $\mathrm{Ib}$ indicates land types with exposed rock (country rock, stones or boulders), which covers $60-80 \%$ of the area. This land type consists of three terrain units, crests comprising $20 \%$ of the land type, mid slopes comprising $75 \%$ of the land type, and valley bottoms constituting the remaining $5 \%$ of the land type. Soils are mostly medium sandy clay loam to sandy clay and shallower than $900 \mathrm{~mm}$ (Land Type Survey Staff 1989).

The land type Ic refers to land types with exposed rock (country rock, stones or boulders), covering more than $80 \%$ of the area. This land type consists of four terrain units, crests comprising $10 \%$ of the land type, scarps comprising $20 \%$ of the land type, mid slopes comprising $68 \%$ of the land type, and valley bottoms constituting the remaining $2 \%$ of the land type. Soils are mostly fine to medium sandy loam to sandy clay loam and shallower than $300 \mathrm{~mm}$ (Land Type Survey Staff 1989).

\section{Climate}

The average annual rainfall for the study area, as measured by a weather station situated on the Jongmanspruit farm (234) for the period $05 / 1999$ to $04 / 2004$ was $561 \mathrm{~mm}$, with a high of $953 \mathrm{~mm}$ and a low of $255 \mathrm{~mm}$ recorded in 2000 and 2002, respectively. For the period $05 / 1999$ to $04 / 2004$, average monthly rainfall varied from $0.7 \mathrm{~mm}$ during the dry winter season (May to October) to $106 \mathrm{~mm}$ in the wet summer season (November to April) (Fig. 2).

For the larger Hoedspruit region, average annual rainfall for the period $05 / 1999$ to $04 / 2004$ was $900 \mathrm{~mm}$ with a high of $1463 \mathrm{~mm}$ and a low of $629 \mathrm{~mm}$ recorded in 2000 and 2002 , respectively. For the period $05 / 1999$ to $04 / 2004$, average monthly rainfall varied from $2 \mathrm{~mm}$ during the dry winter season (May to October) to $189 \mathrm{~mm}$ in the wet summer season (November to April) (Fig. 2).

Rainfall recorded for the study area is less than that of the larger Hoedspruit region due to the study area's location on the foothills of the Drakensberg Mountains along the great escarpment. The mountains form a barrier causing a rain shadow which could be responsible for less rainfall in the study area. However, the mountains do function as an important catchment for the study area and are the source of several small mountain 
streams (Van Zyl 2003). Thunderstorms and fog are the main sources of precipitation for the study area.

Average annual temperature for the study area for the period $05 / 1999$ to $04 / 2004$ was $22{ }^{\circ} \mathrm{C}$, with mean temperatures varying from $17^{\circ} \mathrm{C}$ during the dry winter season to $26^{\circ} \mathrm{C}$ in the wet summer season (Fig. 2). A minimum temperature of $3{ }^{\circ} \mathrm{C}$ and a maximum of $42{ }^{\circ} \mathrm{C}$ were recorded in the $05 / 2003$ to $04 / 2004$ period.

Temperatures for the study area are higher than those for the larger Hoedspruit region due to the study area lying along the northfacing footslopes of the Drakensberg Mountains along the great escarpment. The study area has more direct exposure to sunlight and is more sheltered from southerly winds than the surrounding areas (Tyson \& Preston-Whyte 2000).

\section{Methods}

\section{Vegetation classification and description}

Using a 1:10 000 digitised ortho photo for the Blydeberg area, the study area was stratified into physiognomic-physiographic units (Barbour et al. 1987; Kent \& Coker 1997). A total of 49 sample plots were located in a randomly stratified manner within these units to ensure that all variations in the vegetation were considered and sampled. Plot sizes were fixed at $400 \mathrm{~m}^{2}$ (Barbour et al. 1987; Brown \& Bredenkamp 1994; Brown 1997). In each sample plot, all species were recorded, all woody species counted, and cover abundance was assessed using the BraunBlanquet cover abundance scale (Mueller-Dombois \& Ellenberg 1974; Barbour et al. 1987). Fieldwork was undertaken during April, May, and June 2003 as well as in January 2004. In the light of taxon names constantly changing, this publication conforms to those of Arnold \& De Wet (1993). Structural terminology for the woody species is according to Edwards (1983).

Environmental data collected included aspect, estimates of slope, percentage rockiness and percentage erosion. Floristic data was analysed using the TURBOVEG suite (Hennekens 1996a), which includes the Two-way indicator species analysis multivariate classification technique TWINSPAN (Hill 1979) for deriving an initial approximation of the main plant communities. This numerical classification technique is regarded as a successful approach to vegetation classification by various phytosociologists (Brown \& Bredenkamp 1994; Bredenkamp \& Bezuidenhout 1995; Brown et al. 1996; Cilliers 1998). The visual editor MEGATAB by Hennekens (1996b) was used to generate a phytosociological table. Further refinement of the classification was undertaken through the application of Braun-Blanquet procedures (Barbour et al. 1987; Bredenkamp et al. 1989; Kooij et al. 1990; Bezuidenhout 1993; Eckhardt 1993; Brown \& Bredenkamp 1994; Kent \& Coker 1997). Using the final phytosociological table and habitat information collected during sampling in the field, different plant communities were identified, described and ecologically interpreted.

Erosion was estimated within the following classes (Matthee \& Van Schalkwayk 1984): Class 1 = slight; Class 2 moderate loss of topsoil with slight soil cutting by run-off channels or gullies; Class $3=$ Severe loss of topsoil with marked soil cutting by run-off channels or gullies; Class $4=$ Total loss of topsoil and exposure of subsoil or deep intricate soil cutting by gullies. Slope was estimated within the following categories: level $=0-3^{\circ}$; gentle $=3-8^{\circ}$; moderate $=8-16^{\circ} ;$ steep $=16-26^{\circ}$; very steep $=26-45^{\circ}$.

A variation of the Gradient Analysis Ordination Techniques (Barbour et al. 1987; Kent \& Coker 1997) was used for community ordination. Each community's vegetation cover was split into four cover classes i.e. tree, shrub, herb and grass cover. Using MS Excel, the arithmetic mean for each cover class per community was calculated. Average percentages were plotted for each community, and for each cover class a moving average was calculated using the least squares method. The moving averages were used to generate trend lines that predict potential future tendencies in cover classes across communities. The same procedure was followed for slope, erosion and rockiness.

\section{Plant community selection}

Electivity of available plant communities was calculated using Ivlev's electivity index, i.e., Plant community Electivity $=r_{i}-n_{i} / r_{i}+n_{i}$ where $r_{i}=$ proportion of community utilised and $n_{i}=$ proportion of community available in home range (Krebs 1989). The proportion of a community utilised was calculated as a percentage of all the communities size; the proportion of a community's availability within the home range was calculated as a percentage of the size of all communities. Values for Ivlev's electivity index range between -1 and $1 ;>0$ indicates positive selec- 
tion of a food item; $<0$ indicates selection against, or avoidance of a food item.

\section{Results}

\section{Vegetation classification}

The analysis resulted in the identification of the following ten plant communities (Fig. 3), which may be grouped into four major community types (Table 1):

1. Eragrostis lehmanniana-Grewia flava Shrubland.

1.1 Heteropogon contortus-Grewia flava Shrubland.

1.2 Ziziphus mucronata-Grewia flava Shrubland.

2. Bridelia mollis-Acacia nigrescens Woodland.

2.1 Berchemia zeyheri-Acacia nigrescens Woodland.

2.2 Combretum imberbe-Acacia nigrescens Woodland.

3. Acacia nigrescens-Combretum apiculatum Woodland.

4. Gymnosporia glaucophylla-Panicum maximum Woodland.

4.1 Balanites maughamii-Panicum maximum Woodland.

4.2 Sclerocarya birrea-Panicum maximum Woodland.

4.3 Combretum zeyheri-Panicum maximum Woodland.

4.4 Asparagus setaceus-Philenoptera violacea Woodland.

4.4.1 Pappea capensis Variant.

4.4.2 Diospyros mespiliformis Variant.

\section{Description of plant communities}

The study area is mostly open woodland with a depleted herbaceous layer due to a history of overgrazing and irregular agricultural practices leading to a low plant species diversity. There is a strong presence of the shrub species Grewia flava and Grewia flavescens throughout the study area.

The general vegetation of the study area is characterised by the presence of species from species groups $\mathrm{O}, \mathrm{P}$ and $\mathrm{Q}$ occurring in communities 1,2, 3 and 4; and with species from species group $\mathrm{N}$ found mostly in communities 1, 2 and 3. For all species groups refer to Table 1.
Prominent species include: the shrubs Grewia flavescens, Grewia flava (species group Q), Dichrostachys cinerea (species group $\mathrm{P}$ ); the grass Elionurus muticus (species group Q) which occur in all communities; and the trees Combretum apiculatum and Ziziphus mucronata (species group P) which occur in most communities, with the exception of the Diospyros mespiliformis variant (4.4.2.). The tree Sclerocarya birrea (species group $\mathrm{O}$ ) is prominent in most communities except sub-community 4.4. While the tree Acacia nigrescens (species group $\mathrm{O}$ ) is dominant in communities 1, 2, 3 and subcommunity 4.1 (Table 1).

Table 2 depicts additional plant species recorded for Blydeberg but not significant enough to be reflected in Table 1. The species names and the communities they occur in are presented.

1. Eragrostis lehmanniana-Grewia flava Shrubland

This shrubland plant community covers approximately $24 \%$ of the study area (193 ha) and consists of flat rocky terrain with the vegetation in various stages of degradation (Fig. 3). Soils are sandy, gravelly and relatively well drained. Rock cover for this community varies between 20-45\% and erosion is estimated at $15 \%$.

Species belonging to species group A are diagnostic for this community and include the tree Sterculia rogersii; the grasses Eragrostis lehmanniana, Aristida congesta, A. stipitata; and the forbs Sida cordifolia and Corchorus kirkii.

Vegetation is dominated by the trees Acacia nigrescens, Sclerocarya birrea (species group O), Ziziphus mucronata and Combretum apiculatum (species group P), while the shrubs Dichrostachys cinerea (species group P), Grewia flava, Grewia flavescens (species group Q) are also prominent. The grass layer is not well developed and includes Elionurus muticus (species group Q), Panicum maximum (species group F) and Eragrostis lehmanniana (species group A). 
Portions of this community were previously used for cultivation purposes and are in various stages of secondary succession as can be seen from the large number of different species that are prominent within this community. This community is divided into two sub communities. Although they are delineated on the vegetation map, small sections of sub community 1.1 form a mosaic distribution pattern within sub community 2.2 and could therefore not be mapped.

\subsection{Heteropogon contortus-Grewia flava Shrubland}

The Heteropogon contortus-Grewia flava sub-community is situated in three small areas in the northwest and central sections of the study site (Fig. 3). This sub-community covers $3 \%$ of the study area (20 ha) and $10 \%$ of community 1 , and occurs on what appears to be more disturbed sites or pockets. The areas are relatively rocky (20\% rock cover) and fairly open. Erosion is estimated at $15 \%$ with gentle slopes. Soils are mostly sandy and gravelly.

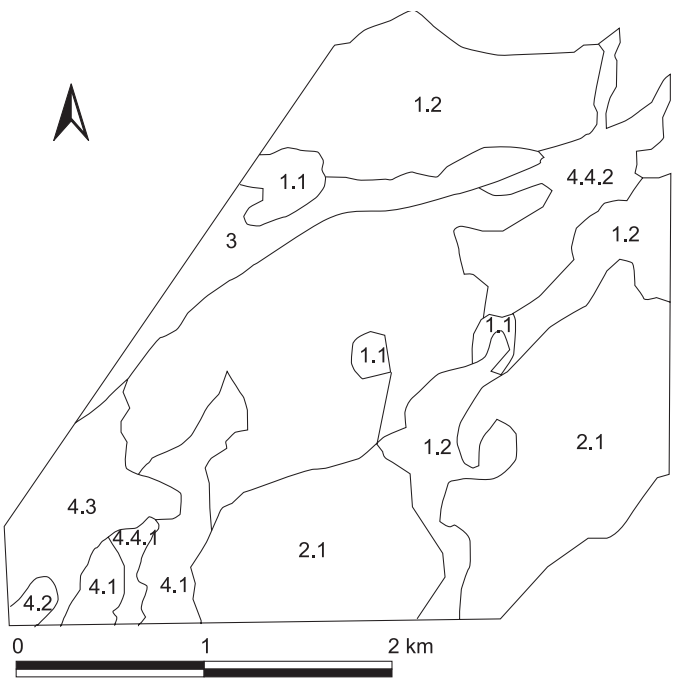

Fig. 3. Vegetation map of the study area within the Blydeberg Conservancy. Map depicts the various communities, sub-communities and variants.
The grasses Heteropogon contortus, Digitaria eriantha and Pogonarthria squarrosa (species group B) are diagnostic for this subcommunity.

The vegetation is dominated locally by the trees Combretum apiculatum (species group P), Acacia nigrescens and Sclerocarya birrea (species group O) together with the shrubs Dichrostachys cinerea (species group P), and Grewia flavescens (species group Q). The herbaceous layer is not well developed and include the grasses Eragrostis lehmanniana (species group A), Digitaria eriantha, Heteropogon contortus (species group B) and Panicum maximum (species group F).

The average number of plant species per $400 \mathrm{~m}^{2}$ in this sub-community is 17 . The tree layer has a 10-60\% cover with an average of $37 \%$; the shrub layer has a $10-70 \%$ cover with an average of $29 \%$; the herb layer has a $0-5 \%$ cover with an average of $2 \%$; and the grass layer has a $1-70 \%$ cover with an average of $26 \%$. The shrub Dichrostachys cinerea has the highest density of 5333 individuals/ha followed by the tree Acacia nigrescens with 2583 individuals/ha and the shrub Acacia karroo with 2167 individuals/ha.

\subsection{Ziziphus mucronata-Grewia flava Shrubland.}

This sub-community comprises two separate sections. One section is located on the northern boundary of the study area while the other is situated on the eastern boundary extending towards the southern boundary in a narrow strip, isolating sub-community 2.1 from the rest of the study area (Fig. 3). This sub-community covers $21 \%$ of the study area (173 ha) and $90 \%$ of community 1 , being flat and relatively open with signs of prior mismanagement in the form of bush encroachment and several stands of samesized and aged trees occurring within this sub-community. The areas are quite rocky $(45 \%)$. Erosion is estimated at $15 \%$ with gentle slopes. Soils are mostly sandy, gravelly and relatively deep. 


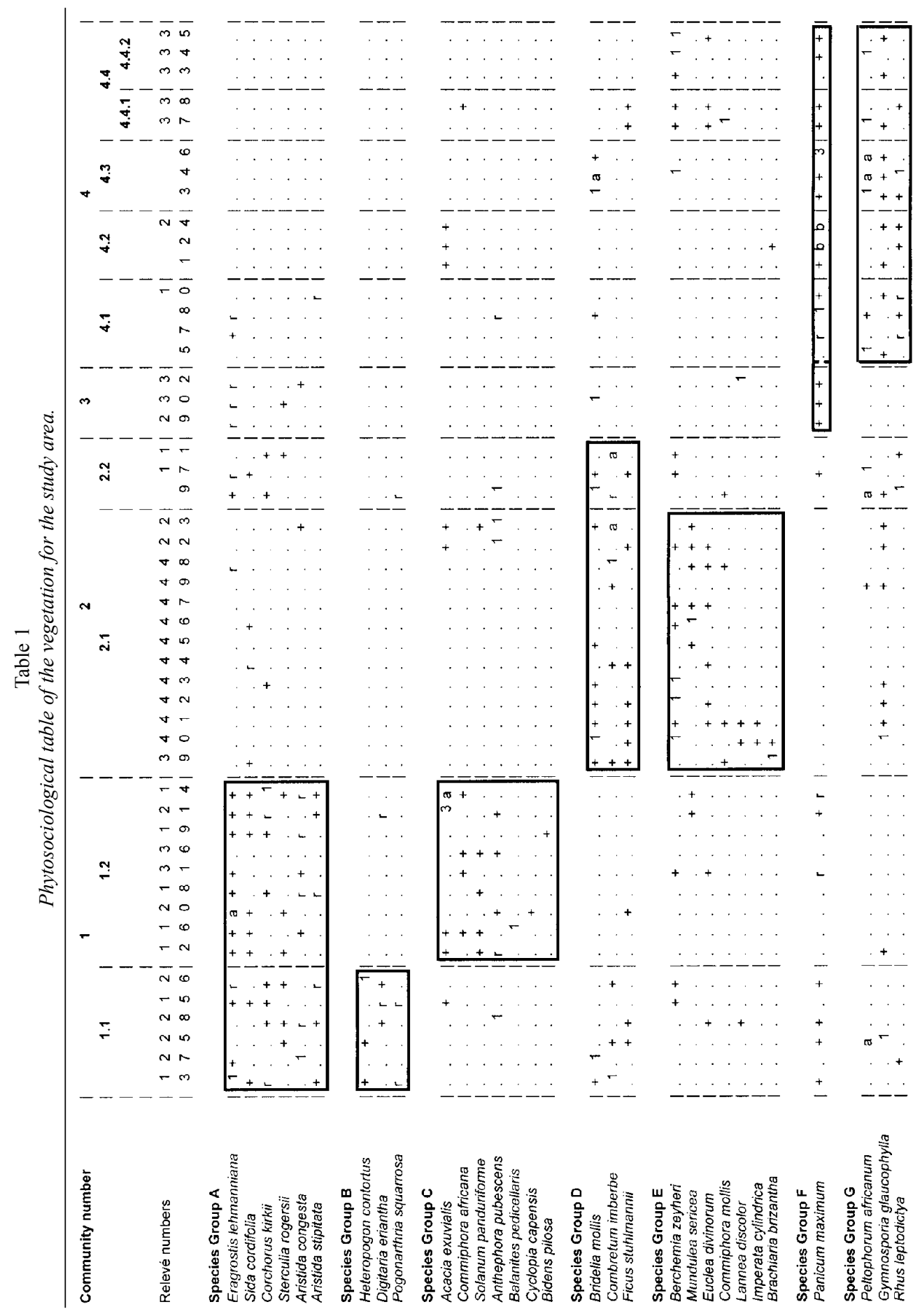




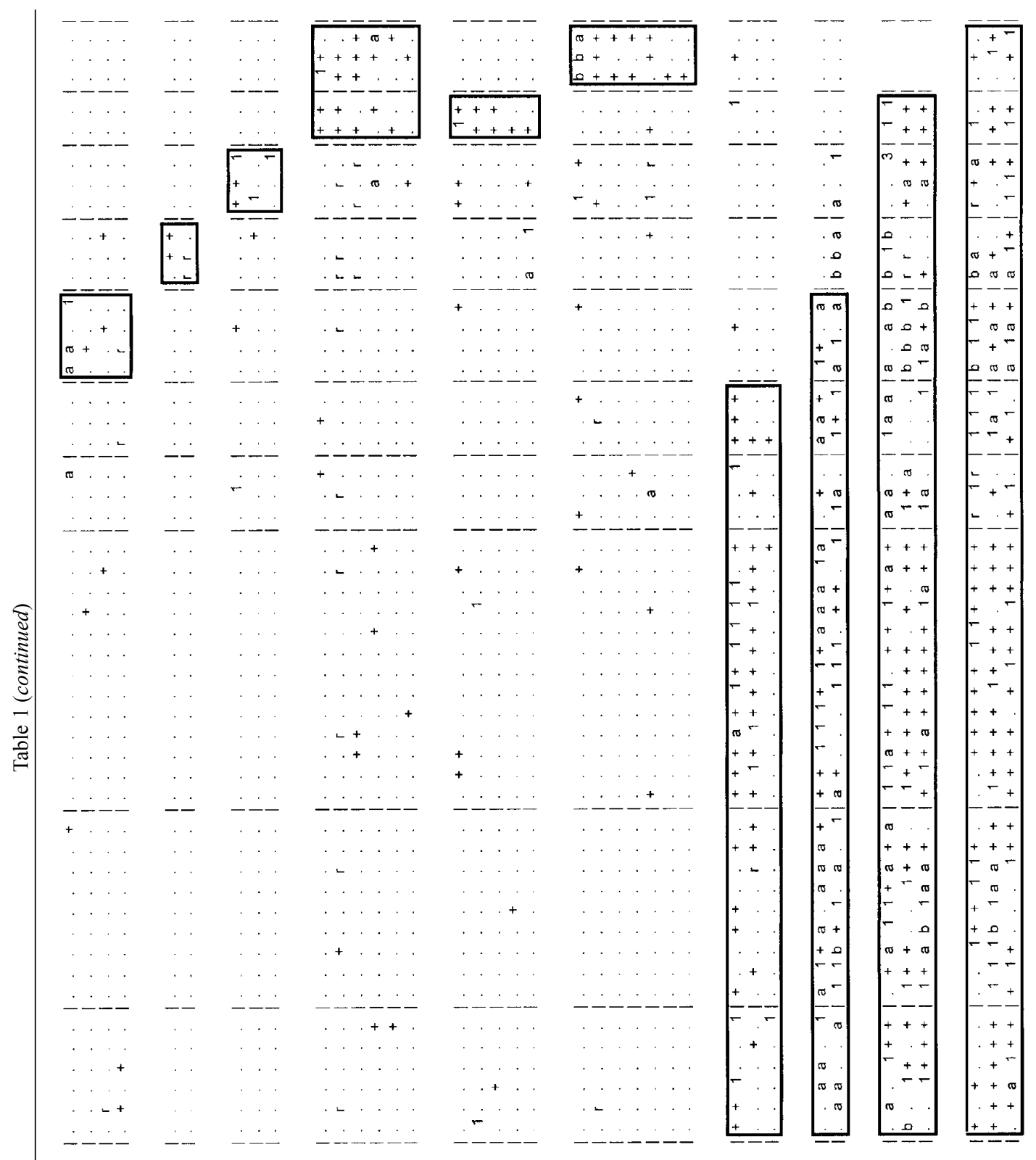

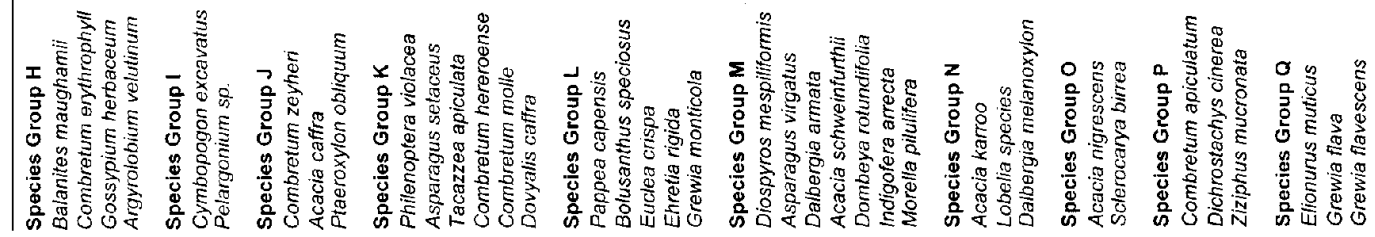


Table 2

Table of less prevalent plant species occurring at Blydeberg and not represented in table 1

\begin{tabular}{lclc}
\hline Species Name & Community Number & Species Name & Community Number \\
\hline Acacia burkei & $1.1,2.1$ & Melinis repens & 2.2 \\
Acacia galpinii & 1.1 & Nuxia oppositifolia & 4.4 \\
Acacia tortilis & 1.1 & Olea europaea & $2.1,4.1$ \\
Aloe dyeri & 1.2 & Opuntia ficus-indica & 2.2 \\
Aloe marlothii & $4.1,4.2$ & Ozoroa paniculosa & $1.2,2.2$ \\
Asparagus cooperi & $1.1,3$ & Ozoroa sphaerocarpa & 4.2 \\
Bacchar adoensi v. kot & 2.1 & Pavonia columella & $4.2,4.4$ \\
Boscia albitrunca & $1.2,2.2$ & Plectroniella armata & 2.2 \\
Canthium ciliatum & 2.1 & Rauvolfia caffra & 4.3 \\
Capparis tormentosa & 4.3 & Rhigozum obovatum & 1.1 \\
Celtis africana & 4.4 & Rhus dentata & 4.4 \\
Chloris virgata & 1.1 & Rhus tumulicola & 4.3 \\
Cussonia spicata & 1.1 & Schotia brachypetala & 4.1 \\
Diheteropogo filifoliu & 1.2 & Scolopia zeyheri & 4.4 \\
Eragrostis rigidior & 4.4 & Spirostachys africana & 4.4 \\
Eragrostis superba & 2.1 & Strelitzia nicolai & 1.2 \\
Eustachys paspaloides & 4.2 & Strophanthus gerrardii & $4.2,4.3$ \\
Ficus sycomorus & 4.3 & Strophanthus speciousus & 4.3 \\
Garcinia livingstonei & 4.3 & Tagetes minuta & $1.1,1.2$ \\
Hippocratea crenata & 4.3 & Terminalia sericea & $1.1,2.1$ \\
Hyparrhenia hirta & 1.2 & Trichilia emetica & 4.4 \\
Hypoxis hemerocallidea & 1.1 & Vernonia adoensis & 2.1 \\
Leucosidea sericea & 1.2 & Wachendorfia parviflor & 4.2 \\
Maerua angolensis & 4.1 & Xanthium spinosum & 2.1 \\
Markhamia zanzibarica & 4.2 & & \\
\hline & & & \\
\hline
\end{tabular}

The trees Acacia exuvialis, Commiphora africana, the shrub Balanites pedicellaris, the herbs Cyclopia capensis and Bidens pilosa, the grass Anthephora pubescens, and the forb Solanum panduriforme (species group C) are diagnostic species for this subcommunity.

The vegetation is dominated by the trees Acacia nigrescens (species group O), Ziziphus mucronata, Combretum apiculatum (species group P); and the shrub Grewia flava (species group Q). The tree Sclerocarya birrea (species group $\mathrm{O}$ ) is also very prominent within this sub-community. The herbaceous layer comprises the grasses Elionurus muticus (species group Q) and Eragrostis lehmanniana (species group A) that are locally prominent. The pioneer forbs Bidens pilosa and Solanum panduriforme (species group C) are also present.
The average number of plant species is $15 / 400 \mathrm{~m}^{2}$ in this sub-community. The tree layer has a 5-80\% cover with an average of $46 \%$; the shrub layer has a 5-90\% cover with an average of $42 \%$; the herb layer has a $0-80 \%$ cover with an average of $17 \%$; and the grass layer has a $1-70 \%$ cover with an average of $17 \%$. The tree Acacia exuvialis has the highest density (6000 ind/ha), followed closely by the shrub Grewia flava (5222 ind/ha) and the tree Ziziphus mucronata with $2667 \mathrm{ind} / \mathrm{ha}$.

\section{Bridelia mollis-Acacia nigrescens Woodland.}

The Bridelia mollis-Acacia nigrescens Woodland comprises the largest proportion of the study area and covers $51 \%$ (415 ha) of the conservancy (Fig. 3). Soils are mostly sandy and well drained with a non-perennial 
mountain stream passing through the centre of this community. Rock cover and erosion for this community varies between 25-35\% and $10-15 \%$, respectively.

Species belonging to species group D are diagnostic for this community and include the trees Ficus stuhlmannii, Combretum imberbe and Bridelia mollis.

The vegetation is dominated by the trees Acacia nigrescens (species group O), Combretum apiculatum (species group $\mathrm{P}$ ) and Acacia karroo shrubs (species group N). The trees Bridelia mollis (species group D) and Sclerocarya birrea (species group O) are locally prominent. Other species also present include the shrubs Dichrostachys cinerea (species group P), Grewia flava, Grewia flavescens (species group Q), and the grass Elionurus muticus (species group Q). The grass species Anthephora pubescens (species group C) occurs sparsely in the community, being locally dominant.

Within this community there are signs of previous overgrazing with old kraals, dipping structures and various old farming implements found in various locations throughout the area. This community consists of two sub-communities.

\subsection{Berchemia zeyheri-Acacia nigrescens Woodland.}

The Berchemia zeyheri-Acacia nigrescens sub-community is located in two large areas in the southern and southeastern sections of the study area (Fig. 3). This sub-community is relatively large - $28 \%$ of the study area (226 ha) and $54 \%$ of community 2 -and occurs in areas where there are signs of historical disturbance, particularly overgrazing with some relics of agricultural farming found within the area. The areas are flat with gentle slopes and sandy soils with intermittent rocks scattered throughout $35 \%$ rockiness). There is slight evidence of erosion in the form of small furrows at places $(10 \%$ erosion).

The trees Berchemia zeyheri, Commiphora mollis, Lannea discolor, the shrubs Mun- dulea sericea, Euclea divinorum, and the grasses Imperata cylindrica and Brachiaria brizantha (species group E) are diagnostic for this sub-community.

The woody layer comprises a mixture of species with the vegetation dominated by the trees Acacia nigrescens (species group $\mathrm{O}$ ), Combretum apiculatum (species group $\mathrm{P}$ ), and Acacia karroo shrubs (species group N). The trees Berchemia zeyheri (species group E), Sclerocarya birrea (species group O) and Ziziphus mucronata (species group P) are locally prominent, while the shrubs Grewia flava, Grewia flavescens (species group Q), Gymnosporia glaucophylla (species group $\mathrm{G}$ ), the grass Elionurus muticus (species group Q) and the forb Lobelia species (species group N) are also present.

The average number of plant species is 16/ $400 \mathrm{~m}^{2}$ in this sub-community. The tree layer has a $10-80 \%$ cover with an average of $46 \%$; the shrub layer has a 5-80\% cover with an average of $34 \%$; the herb layer has a $1-30 \%$ cover with an average of $8 \%$; and the grass layer has a $1-60 \%$ cover with an average of $20 \%$. The shrub Acacia karroo has the highest density of $5615 \mathrm{ind} /$ ha followed by the trees Acacia nigrescens with $3962 \mathrm{ind} / \mathrm{ha}$ and Combretum apiculatum with $3308 \mathrm{ind} / \mathrm{ha}$.

\subsection{Combretum imberbe-Acacia nigrescens Woodland.}

This sub-community is located centrally and towards the western boundary of the study area, east of community 3 that forms part of the western boundary of the study area (Fig. 3). This woodland is relatively large covering $23 \%$ of the study area (189 ha) and $46 \%$ of community 2 , and is mainly flat and open with signs of mismanagement in the form of previous overgrazing. Rockiness is estimated at $25 \%$ with most rocks occurring adjacent to a dry river bed. Erosion is estimated at $15 \%$. The area has a gentle slope with soils being predominantly sandy and well drained. 
Characteristic of this sub-community is the absence of species from species group E. The trees Peltophorum africanum (species group G), Combretum apiculatum, Ziziphus mucronata (species group P) and the shrub Dichrostachys cinerea (species group P) dominate the vegetation. Other species also present are the tree Bridelia mollis (species group D), the shrub Corchorus kirkii (species group A) and the grass Elionurus muticus (species group Q) being locally prominent.

The average of 18 plant species per $400 \mathrm{~m}^{2}$ are found in this sub-community. The tree layer has a $30-90 \%$ cover with an average of $60 \%$; the shrub layer has a 5-40\% cover with an average of $18 \%$; the herb layer has $0 \%$ cover; and the grass layer has a $1-40 \%$ cover with an average of $19 \%$. The shrub Dichrostachys cinerea has the highest density of $5500 \mathrm{ind} / \mathrm{ha}$, with the tree Combretum apiculatum having $2500 \mathrm{ind} / \mathrm{ha}$ and the shrub Grewia flavescens having $1667 \mathrm{ind} / \mathrm{ha}$.

\section{Acacia nigrescens-Combretum apiculatum Woodland.}

This woodland community forms part of the western boundary of the study area comprising approximately $6 \%$ (48 ha) of the study area (Fig. 3). Slope is moderate with shallow soils as most of the community is on a rocky protrusion. Average erosion for this community is estimated at $10 \%$, with average rockiness estimated at $15 \%$.

The Acacia nigrescens-Combretum apiculatum Woodland is characterised by the absence of any diagnostic species. Also characteristic of this woodland is the presence of species group $\mathrm{F}$ and the absence of species groups $\mathrm{G}$ to $\mathrm{M}$. Vegetation is dominated by the trees Combretum apiculatum (species group P), Acacia nigrescens, Sclerocarya birrea (species group O), the shrub Grewia flava (species group Q), and the grass Elionurus muticus (species group Q).

Characteristic of this community is the absence of the shrubs Dichrostachys cinerea (species group P) that are present in almost all the other communities of the study area. Acacia karroo shrubs (species group N) are also present. This community has a more developed herbaceous layer with the increaser 2 grass Eragrostis lehmanniana (species group A) and the decreaser grass Panicum maximum (species group F) present throughout this community.

There are signs of previous overgrazing by cattle throughout this community, with several old farm implements scattered throughout the community. The dominance of the increaser 3 grass Elionurus muticus is indicative of the degraded condition of the herbaceous layer. However, the presence of the grasses Panicum maximum and Eragrostis lehmanniana is indicative that this community is recovering and in a secondary successional phase.

The average number of plant species in this community is 13 per $400 \mathrm{~m}^{2}$. The tree layer has an average estimated cover of $32 \%$; the shrub layer has an average estimated cover of $18 \%$; the herb layer has an average estimated cover of $1 \%$; and the grass layer has an average estimated cover of $33 \%$. The shrub Grewia flava has a density of $4833 \mathrm{ind} / \mathrm{ha}$; the tree Combretum apiculatum has $4000 \mathrm{ind} / \mathrm{ha}$ and the shrub Acacia karroo has 3333 ind/ha.

\section{Gymnosporia glaucophylla-Panicum maximum Woodland.}

This woodland plant community covers about $20 \%$ of the study area (160 ha) and is mostly mountainous (Fig. 3). Soils are predominantly sandy and relatively well drained. Rock cover for this community varies between $10-50 \%$ and erosion is $10 \%$.

Species belonging to species groups $\mathrm{F}$ and $\mathrm{G}$ are diagnostic for this community and include: the trees Peltophorum africanum, Rhus leptodictya; the shrub Gymnosporia glaucophylla; and the grass Panicum maximum.

The vegetation is dominated by the shrubs Grewia flavescens and Grewia flava (species group Q), while the grass Elionurus muticus (species group Q) is also prominent. The 
trees Combretum apiculatum and Ziziphus mucronata (species group P), and the shrub Dichrostachys cinerea (species group P) are also dominant throughout, except in the Diospyros mespiliformis Variant (4.4.2).

There are many signs of animal activity throughout this community, mainly game tracks, middens and foraging evidence. There are also signs of previous grazing by cattle. A few roads pass through the community and a few small dwellings are present. This community consists of four sub-communities and two variants.

\subsection{Balanites maughamii-Panicum maximum Woodland.}

This sub-community is located in the south western section of the study area and consists of two separate areas split by the Pappea capensis Variant (Fig. 3). This sub-community covers $5 \%$ of the study area (43 ha) and $27 \%$ of community 4 , and is found on the relatively steep, predominantly northfacing footslopes of the Drakensberg mountain range constituting the southern boundary of the study area. There are signs of previous cattle grazing in the lower lying areas. The areas are relatively rocky $(30 \%)$. Erosion is estimated at $10 \%$ with a moderate to steep slope. Soils are mostly sandy.

The trees Combretum erythrophyllum and Balanites maughamii; the shrub Gossypium herbaceum; and the perennial herb Argyrolobium velutinum (species group $\mathrm{H}$ ) are diagnostic for this community.

The woody layer comprises a mixture of species with the vegetation dominated by the trees Combretum apiculatum, Ziziphus mucronata (species group P) and Sclerocarya birrea (species group O), the shrubs Dichrostachys cinerea (species group P) and Grewia flavescens (species group Q), and the grass Elionurus muticus (species group Q). The tree Acacia nigrescens (species group O) and the shrub Grewia flava (species group Q) are also present.

In this sub-community, the average number of plant species is 15 per $400 \mathrm{~m}^{2}$. The tree layer has a 40-80\% cover with an average of $55 \%$, the shrub layer has a $20-50 \%$ cover with an average of $30 \%$, the herb layer has $1 \%$ cover, and the grass layer has a $40-60 \%$ cover with an average of $49 \%$. The shrub Dichrostachys cinerea has the highest density (8000 ind/ha), followed by the shrubs Grewia flavescens (5750 ind/ha) and Grewia flava (4125 ind/ha).

\subsection{Sclerocarya birrea-Panicum maximum Woodland.}

This is a small sub-community occupying the southwestern corner of the study area (Fig. 3). This woodland covers $1 \%$ of the study area ( 5 ha) and $3 \%$ of community 4 . The area is steep and has a large cliff-like rock face forming part of its eastern boundary. There are many signs of wild animal activity and several animal tracks traverse this sub-community. Rockiness and erosion are estimated at $30 \%$ and $10 \%$, respectively. Soils are predominantly sandy and shallow.

The grass Cymbopogon excavatus and the herbaceous shrublet Pelargonium sp. (species group I) are diagnostic for this subcommunity.

The vegetation is dominated by the trees Sclerocarya birrea (species group O) and Combretum apiculatum (species group P). The shrub Grewia flavescens (species group Q) and the grass Elionurus muticus (species group Q) are also very prominent within this sub-community. The tree Acacia exuvialis (species group A) is present.

In this sub-community, the average number of plant species is 15 per $400 \mathrm{~m}^{2}$. The tree layer has a 30-80\% cover (average $47 \%$ ); the shrub layer has a 5-80\% cover (average $42 \%$ ); the herb layer has $0-1 \%$ cover (average $1 \%$ ); and the grass layer has a 40-90\% cover (average $70 \%$ ). The tree Combretum apiculatum has the highest density (5000 ind/ ha), followed by the tree Sclerocarya birrea (2333 ind/ha) and the shrub Grewia flavescens (2333 ind/ha). 
4.3 Combretum zeyheri-Panicum maximum Woodland.

This sub-community is found in the south western section of the study area (Fig. 3). This woodland covers $6 \%$ of the study area ( 51 ha) and constitutes $32 \%$ of community 4 . The area is moderate to steep in the south, gradually becoming moderate towards the north. A few small dwellings are found within this sub-community. There are many signs of wild animal activity and some signs of previous human agricultural disturbance. Old farm implements are lying in the veld and small unused man-made dams are found. Open areas, with stands of similar-sized and aged Dichrostachys cinerea shrubs occur throughout, indicating overgrazing by cattle. Rockiness and erosion are estimated at $45 \%$ and $10 \%$, respectively. Soils are sandy and shallow in the south, becoming deeper towards the north.

The trees Acacia caffra and Combretum zeyheri and the shrub Ptaeroxylon obliquum (species group J) are diagnostic for this subcommunity.

The vegetation is dominated by the trees Sclerocarya birrea (species group O) and Combretum apiculatum (species group P) and the shrub Grewia flavescens (species group Q). The shrub Dichrostachys cinerea (species group $\mathrm{P}$ ) and the grass Elionurus muticus (species group Q) are also prominent within this sub-community. There is also a strong presence of the tree Bridelia mollis (species group D).

The average number of plant species in this sub-community is 17 per $400 \mathrm{~m}^{2}$. The tree layer has a 70-80\% cover (average of $73 \%$ ); the shrub layer has a $15-70 \%$ cover (average of $35 \%$ ); the herb layer has a $0-1 \%$ cover (average of $1 \%$ ); and the grass layer has a $1-80 \%$ cover (average of $29 \%$ ). The tree Combretum apiculatum has the highest density (4500 ind/ha), the shrub Dichrostachys cinerea has 3833 ind/ha, and the shrub Grewia flavescens has $3500 \mathrm{ind} / \mathrm{ha}$.
4.4 Asparagus setaceus-Philenoptera violacea Woodland.

This woodland sub-community consists of two variants, the Pappea capensis Variant located in the south western section of the study area, and the Diospyros mespiliformis Variant located in the north eastern section (Fig. 3). This sub-community covers approximately $8 \%$ of the study area (61 ha) and $38 \%$ of community 4 . The terrain ranges from steep (the Pappea capensis Variant) to gentle (the Diospyros mespiliformis Variant). Rockiness for this sub-community varies between $10-50 \%$ and erosion is $10 \%$. Soils are predominantly sandy and well drained.

The trees Philenoptera violacea, Combretum hereroense and Combretum molle, the shrub Dovyalis caffra, and the herbs Asparagus setaceus and Tacazzea apiculata (species group K) are diagnostic for this sub-community.

The vegetation is dominated by the shrub Grewia flavescens (species group Q). The shrub Grewia flava (species group Q) and the grass Elionurus muticus (species group Q) are also prominent within this sub-community. There is also a strong presence of the tree Berchemia zeyheri (species group E).

There are signs of previous and current human disturbance in the form of old cattle dipping structures, old cattle kraals, recent vegetation removal for development, a few recently constructed log cabins and a new earthen dam.

\subsubsection{Pappea capensis Variant}

This variant is located on the north-facing midslopes and footslopes of the Drakensberg mountains in the southeastern section of the study area and divides the Balanites maughamii-Panicum maximum Woodland subcommunity (4.1) into an eastern and western section (Fig. 3). This variant covers $1 \%$ of the study area ( $7 \mathrm{ha}$ ) and $11 \%$ of subcommunity 4.4 , and is found on the moderate to steep midslopes and footslopes of the Drakensberg mountain range. Signs of human disturbance include previous cattle 
a)

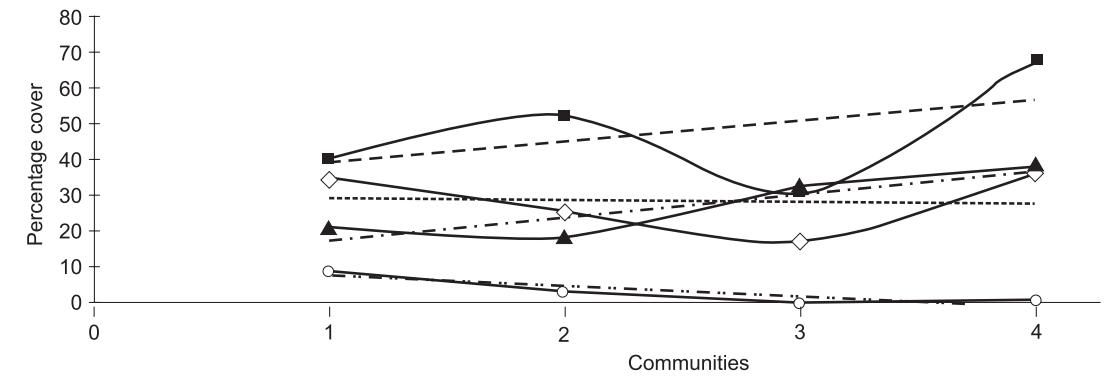

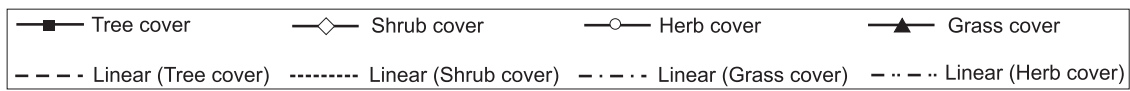

b)

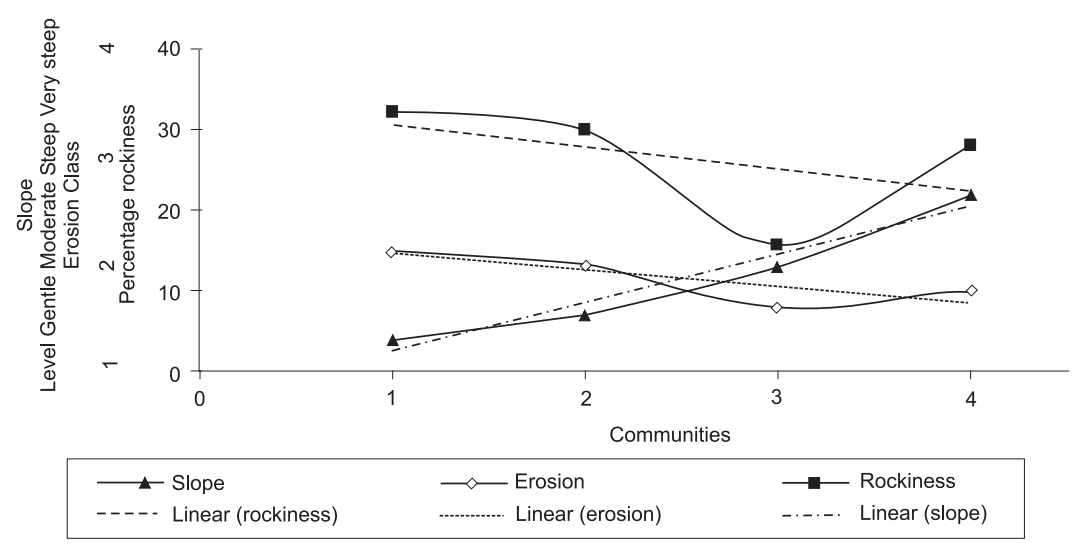

Fig. 4. Community ordination scatter diagrams depicting a) tree cover, shrub cover, herb cover, and grass cover with trend lines portraying tendencies in the aforementioned parameters from community 1 through community 4 ; and b) slope, erosion and rockiness with trend lines depicting inclinations of aforementioned parameters from community 1 through community 4 .

dipping structures and kraals. Rockiness is estimated at $50 \%$ and erosion is estimated at $10 \%$. Soils are sandy.

The tree Pappea capensis and the shrubs Bolusanthus speciosus, Euclea crispa, Ehretia rigida and Grewia monticola (species group L) are diagnostic for this variant.

The vegetation is dominated by the tree Combretum apiculatum (species group P) and the shrub Grewia flavescens (species group Q). The tree Commiphora mollis (species group E) and the grass Elionurus muticus (species group Q) are also prominent. The trees Ziziphus mucronata (species group P), Ficus stuhlmannii (species group D) and Berchemia zeyheri (species group E); and the shrubs Dichrostachys cinerea (species group P), Grewia flava (species group Q) and Euclea divinorum (species group E) are also present. 


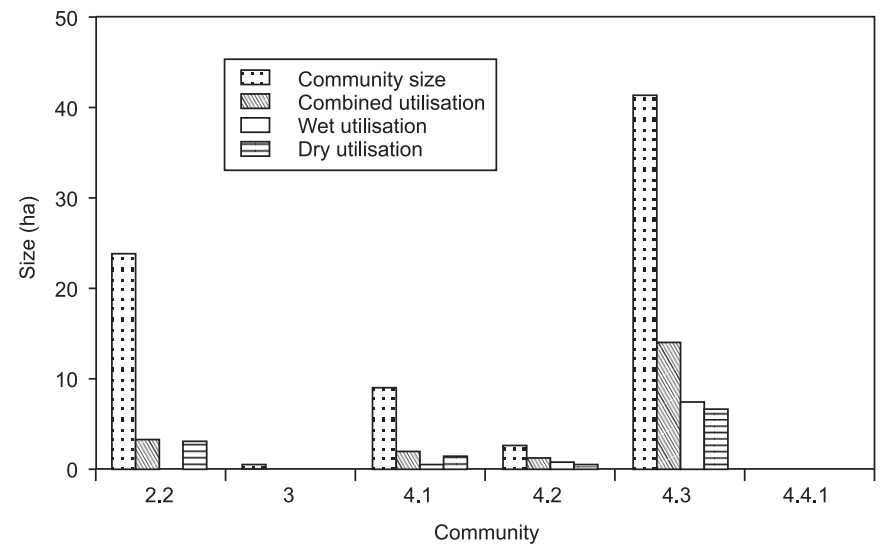

Fig. 5. Community utilisation by vervets for wet and dry seasons in the Blydeberg Conservancy.

The average number of plant species $/ 400 \mathrm{~m}^{2}$ is 22 . The tree layer covers $70-90 \%$, the shrub layer $15-60 \%$; the herb layer $2-5 \%$; and the grass layer $20-70 \%$ of the area. The shrub species Grewia flavescens has the highest density of $2500 \mathrm{ind} / \mathrm{ha}$, the tree species Combretum apiculatum having 1750 ind/ha and the shrub species Grewia flava with $1500 \mathrm{ind} / \mathrm{ha}$.

\subsubsection{Diospyros mespiliformis Variant}

This variant is located in the north eastern section of the study area (Fig. 3), covering 7 $\%$ of the study area (54 ha) and $89 \%$ of subcommunity 4.4. Slope is gentle. A dry river bed with several large riverine trees growing adjacent to the river bed runs through the area. There are many signs of recent human disturbance throughout this variant. Several small wooden cabins and an earthen dam have recently been constructed along the river bed due to the shady and aesthetic nature of the area. A portion of the variants vegetation has also been removed for development. Average erosion for this community is estimated at $10 \%$, with average rockiness also estimated at $10 \%$. Soils are deep, sandy and well drained.

Species belonging to species group $\mathrm{M}$ are diagnostic for this variant and include: the trees Diospyros mespiliformis, Acacia schweinfurthii and Dombeya rotundifolia; the shrubs Indigofera arrecta and Morella pilulifera; the herb Asparagus virgatus; and the liana Dalbergia armata.

The vegetation is dominated by the shrubs Grewia flavescens and Grewia flava (species group Q). The tree Berchemia zeyheri (species group E) is also prominent. The grass layer is not well developed and includes the grasses Panicum maximum (species group F) and Elionurus muticus (species group Q).

The average number of plant species is $16 / 400 \mathrm{~m}^{2}$. The tree layer has an $80-90 \%$ cover with an average of $87 \%$; the shrub layer has a $30-60 \%$ cover with an average of $40 \%$; the herb layer has a $2-3 \%$ cover with an average of $2 \%$; and the grass layer has a $0-5 \%$ cover with an average of $2 \%$. The shrub species Grewia flava has the highest density of $2000 \mathrm{ind} / \mathrm{ha}$, the tree species Berchemia zeyheri has 2000 ind/ha, while 
the tree species Diospyros mespiliformis has $1667 \mathrm{ind} / \mathrm{ha}$.

\section{Ordination}

Figure 4 depicts community vegetation parameters along gradients of slope, erosion and rockiness. There is a general increase in tree cover from community 1 through 4 , with the exception of community 3 which occurs on a rocky protrusion with shallow soils which is more conducive to grasses. An increase in tree cover could be attributed to a decline in erosion and rockiness from community 1 through to community 4 , reaching their respective troughs in community 3 due to the rocky protrusion. Shrub and herb cover decrease from community 1 through 3 , but increase slightly in community 4 ; decreases could be related to a trend of increasing tree cover which blocks sunlight and out competes non-woody vegetation. Increases in slope and decreases in erosion and rockiness (with the exception of community 3 which occurs on a rocky outcrop as mentioned previously) from community 1 through 4 might also be partially responsible for increases in shrub cover for community 4. Grass cover generally increases with increasing slope and decreasing erosion and rockiness from community 1 through 4 , with a slight exception for community 2 which could be attributable to previous mismanagement and overgrazing.

\section{Plant community selection}

Of the ten available plant communities identified within their home range, the vervets only utilised the following six:

- Community 2.2 made up $55.1 \%$ of the study area. During the wet season vervets utilised $0.1 \%$ of the community compared to the $1.6 \%$ in the dry season.

- Community 3 made up $14.0 \%$ of the study area. During the wet season vervets did not use it and during the dry season they utilised only $0.2 \%$.

- Community 4.1 made up $12.5 \%$ of the study area. During the wet season vervets utilised $1.1 \%$ of the community and during the dry season they utilised $3.0 \%$.

- Community 4.2 made up $1.5 \%$ of the study area. During the wet season vervets utilised $13.4 \%$ of the community and during the dry season $13.1 \%$.

- Community 4.3 made up $14.9 \%$ of the study area. During the wet season vervets utilised $14.2 \%$ of the community versus $13.1 \%$ during the dry season.

- Community 4.4 .1 made up $2.0 \%$ of the study area. Vervets did not use this community during the wet season but during the dry season they utilised $1.2 \%$.

Figure 5 depicts community utilisation across seasons for the study area and study period. Community utilisation was not significantly different for wet and dry seasons $(u=23.000, p=0.4233)$.

\section{Discussion and conclusions}

There are relatively clear distinctions between the various communities identified at the Blydeberg Conservancy. The BraunBlanquet approach proved to be an accurate and effective way whereby floristicallydefined plant communities could be classified and identified in the field.

All the plant communities identified in the study area reflect some form of human related impact, mostly due to agricultural practices. With the exception of the Diospyros mespiliformis Variant (4.4.2) all the plant communities identified are in the process of self rectification to a more stable successional stage. In the Diospyros mespiliformis Variant (4.4.2) there are recent signs of largescale vegetation destruction through clearing actions by humans. As this is not consistent with the definition and objectives of a conservancy, i.e., the conservation of the natural resources occurring within the area, this would therefore need to be addressed by the members of the conservancy. A close association between the major plant communities and the different land types has been observed in this study. This is in accordance with the findings of Kooij et al. (1990), Bezuidenhout (1993), Eckhardt (1993) and Brown (1997). 
Many of the low-lying areas within the study area have dense woodlands and a poorly developed herbaceous layer, which could be ascribed to previous long term overgrazing by cattle. The tree densities of all the low lying areas (communities $1.1 ; 1.2 ; 2.1 ; 2.2$ ) are more than $5000 \mathrm{ind} /$ ha which are higher than the threshold value of 1500-1700 ind/ha after which veld condition will decline (Orban 1995). Overgrazing by cattle has compromised the herbaceous layer by removing the natural tree/grass competition factor resulting in areas that appear to be in a semi-degraded condition. A decline in the condition of the grass or herbaceous layer is typically accompanied by an increase in the density of trees and shrubs (Smit et al. 1999). Reduced competition from grass communities in overgrazed areas leads to an increase in the density of woody species. In most cases these changes are irreversible due to woody species out-competing grasses for moisture. Over time, fuel loads are reduced in areas with a degraded grass layer and fire can no longer be used as an effective means of bush control. Since vervets mostly feed in forest/woodland areas, these areas also become more suitable to these species.

This study forms part of a larger study on the foraging ecology of a single troop of vervet monkeys in Mixed Lowveld Bushveld and Sour Lowveld Bushveld of the Blydeberg Conservancy. To date there are no formal management plans for vervet monkeys. This is attributed to the limited knowledge of vervets and their utilisation of and impacts on ecosystems. The study troop's diet consisted of a number of staple food items, with a relatively wide seasonal variation for additional supplementation (Barrett 2005). There was an abundant supply of various food sources throughout the year, with movement patterns mostly coinciding with the fruiting times of several tree and plant species. Home range size appeared to be linked to food and particularly water availability, with the troops' mean daily distance travelled increasing slightly during the dry season (Barrett 2005). With regards to habitat utilisation, the vervets had ten plant communities available to them within their home range.
Of the ten available plant communities, they utilised only six during the study period namely sub-community 2.2 (Combretum imberbe-Acacia nigrescens Woodland), community 3 (Acacia nigrescens-Combretum apiculatum Woodland), sub-community 4.1 (Balanites maughamii-Panicum maximum Woodland), sub-community 4.2 (Sclerocarya birrea-Panicum maximum Woodland), sub-community 4.3 (Combretum zeyheri-Panicum maximum Woodland), and the Pappea capensis Variant (4.4.1) (Barrett 2005). Of the six communities utilised, community 4.2 was used the most during both the wet and the dry season. The Acacia nigrescens-Combretum apiculatum Woodland (Community 3 ) and the Pappea capensis Variant (4.4.1) were only used during the dry season, whereas the other communities were randomly utilised across both seasons (Barrett 2005).

No similar vegetation descriptions have previously been completed on the vegetation of the study area and this research therefore provides valuable data on the ecosystems present. Previous vegetation studies for the region were conducted on broader plant communities (Deall 1985; Deall et al. 1989; Matthews 1991; Matthews et al. 1994; Marais 2005). Data obtained from this initial assessment could be incorporated into a larger vegetation map for the entire Blydeberg conservancy. Setting up goals and objectives for the management of the area would be essential to its continued existence over the medium to long term and should be seen as a priority by all involved. By establishing a set of minimum objectives, a baseline management plan can be developed where the natural vegetation is managed and protected. A veld management and monitoring program needs to be implemented as a priority so that a thorough knowledge of the vegetation; the variability thereof; carrying capacities; quality of veld; reaction of the vegetation to various ecological impacts such as burning, grazing, browsing, bush clearing, invader species etc. and the growth processes of plants in different stages of their life cycles can be understood and managed to the benefit of all animals and humans in the area. 


\section{Acknowledgements}

Professor D. Mitchell is thanked for allowing the research to take place on his privately owned portion of the Blydeberg Conservancy. This research was financially supported by the National Research Foundation.

\section{References}

ARnold, T.H. \& B.C. DE WET. 1993. Plants of Southern Africa: Names and distribution. Memoirs of the botanical Survey of South Africa 62: 1-825.

Barbour, M.G., J.H. BURK \& W.D. PITTS. 1987. Terrestrial Plant Ecology. 2nd ed. Massachusetts: Benjamin/Cummings.

BARRETT, A.S. 2005. Foraging ecology of the vervet monkey (Chlorocebus aethiops) in Mixed Lowveld Bushveld and Sour Lowveld Bushveld of the Blydeberg Conservancy, Northern Province, South Africa. M.Tech. Nature Conservation Dissertation. University of South Africa, Pretoria.

Bezuidenhout, H. 1993. Syntaxonomy and synecology of Western Transvaal Grasslands. Ph.D. dissertation, University of Pretoria, Pretoria.

Bezuidenhout, H. 1996. The major vegetation communities of the Augrabies Falls National Park, northern Cape. 1. The southern section. Koedoe 39: 7-24.

Booth, A.H. 1979. The Distribution of Primates in the Gold Coast. Pp. 139-154. In: Sussman, R.W. (ed.). Primate Ecology. Problem-oriented field studies. New York: Wiley

BREDENKAMP, G.J. \& H. BEZUIDENHOUT. 1995. A proposed procedure for the analysis of large data sets in the classification of South African Grasslands. Koedoe 38(1): 33-39.

BredenKamp, G.J., A.F. Joubert \& H. BezuidenHOUT. 1989. A reconnaissance survey of the vegetation of the plains in the PotchefstroomFochville-Parys Area. South African Journal of Botany 55: 199-206.

Brown, L.R. 1997. A plant ecological and wildlife management plan of the Borakalalo Nature Reserve, North-west Province. Ph.D. dissertation. University of Pretoria, Pretoria.

BRown, L.R. \& G.J. BREDENKAMP. 1994. The phytosociology of the southern section of the Borakalalo Nature Reserve, South Africa. Koedoe 37: 59-72.

BRown, L.R. \& G.J. BRedenKAMP \& N. VAN ROOYEN. 1996. The phytosociology of the northern section of the Borakalalo Nature Reserve. Koedoe 39(1): 9-24.

BuCKLE, C. 1992. Landforms in Africa: An Introduction to Geomorphology. Essex: Longman.
Caughley, G. \& A.R.E. Sinclair. 1994. Wildlife Ecology and Management. Canada: Oxford University Press.

Cilliers, S.S. 1998. Phytosociological studies of urban open spaces in Potchefstroom, North West Province, South Africa. Ph.D. thesis, Potchefstroom University for CHE, Potchefstroom.

Deall, G.B. 1985. A plant-ecological study of the Eastern Transvaal escarpment in the Sabie area. M.sc. thesis, University of Pretoria, Pretoria.

Deall, G.B., G.K. Theron, R.H. Westrall. 1989. The vegetation ecology of the Eastern Transvaal Escarpment in the Sabie area. 2. Floristic classification. Bothalia 19: 69-89.

ECKHARDT, H.C. 1993. A synecological study of the vegetation of the north-eastern Orange Free State. M.Sc. thesis. University of Pretoria, Pretoria.

EDWARDS, D. 1983. A broad-scale structural classification of vegetation for practical purposes. Bothalia 14: 705-712.

Fedigan, L. \& L.M. Fedigan. 1988. Cercopithecus aethiops: a review of field studies. Pp 389-411. In: Gautier-Hion A., Bourlière F., Gautier J., KIngdon J. (eds.). A Primate Radiation: Evolutionary Biology of the African Guenons. New York: Cambridge University Press.

FuLS, E.R. 1993. Vegetation ecology of the northern Orange Free State. Ph.D. dissertation. University of Pretoria, Pretoria.

Fuls, E.R., G.J. BREDENKAMP \& N. VAN RoOyen. 1992. The plant communities of the undulating grassland of the Vredefort-Kroonstad-LindleyHeilbron area, northern Orange Free State. South African Journal of Botany 58: 224-230.

HARRISON, M.J.S. 1983. Patterns of range use by the green monkey, Cercopithecus sabaeus, at Mt. Assirik, Senegal. Folia Primatol 41: 157-179.

HARRISON, M.J.S. 1984. Optimal foraging strategies in the diet of the green monkeys, Cercopithecus sabaeus, at Mt. Assirik, Senegal. International Journal of Primatology 5: 435-471.

Hennekens, S.M. 1996a. TURBOVEG: A software package for input, processing and presentation of phytosociological data. User's guide, version July 1996, IBN-DLO. Lancaster: Wageningen \& Lancaster University.

HenneKens, S.M. 1996b. Megatab: a visual editor for phytosociological tables. Ulft: Giesen.

HILL, M.O. 1979. TWINSPAN: A Fortran program for arranging multivariate data in an ordered twoway table by classification of individuals and attributes. New York: Cornell University.

Isbell, L.A., J.D. Pruetz \& T.P. Young. 1998. Movements of vervets (Cercopithecus aethiops) and patas monkeys (Erythrocebus patas) as estimators of food resource size, density and distribution. Behavioral Ecology and Sociobiology 42: 123-133. 
Kent, M. \& P. COKer. 1997. Vegetation Description and Analysis - A Practical Approach. New York: Wiley.

KingDon, J. 1997. The Kingdon field guide to African Mammals. New York: NaturalWorld.

KoolJ, M.S., G.J. BRedenKAMP \& G.K. Theron. 1990. Classification of the vegetation of the $B$ land type in the north-western Orange Free State. South African Journal of Botany 56: 309318.

KREBS, C. J. 1989. Ecological methodology. New York: Harper and Row.

Land Type Survey Staff. 1989. Land types of the maps 2330 Tzaneen, 2430 Pilgrims Rest. Memoirs on the Agricultural Natural Resources of South Africa 12.

LeE, P.C. \& M.D. Hauser. 1998. Long-term consequences of changes in territory quality on feeding and reproductive strategies of vervet monkeys. Journal of Animal Ecology 67: 347-358.

Low, A.B. \& A.G. ReBelo (eds.). 1998. Vegetation of South Africa, Lesotho and Swaziland. 2nd ed. Pretoria: Department of Environmental Affairs and Tourism.

MARAIS, A.J. 2005. Resource utilisation of the chacma baboon in different vegetation types in northeastern mountain sour veld, Blyde Canyon Nature Reserve. M.Tech. (Nature Conservation) Dissertation. University of South Africa, Pretoria.

MattheE, J.F. \& C.J. van Schalkwyk. 1984. $A$ Primer on Soil Conservation. Pretoria: Government Printer. (Department of Agriculture bulletin; no. 399.)

MatTHEWs, W.S. 1991. Phytosociology of the Northeastern Mountain Sourveld. Msc. Thesis, University of Pretoria, Pretoria.

Matthews, W.S., G.J. BredenKamp \& N. Van ROOYEN. 1994. The phytosociology and syntaxonomy of relative low-altitude areas in the North-eastern Mountain Sourveld, in the eastern Transvaal escarpment region. Koedoe 37(2): 73-87.

Mueller-Dombois, D. \& H. Ellenberg. 1974. Aims and methods of vegetation ecology. New York: Wiley.

OAtes, J.F. 1996. African Primates Status Survey and Conservation Action plan. Gland, Switzerland: IUCN. (IUCN/SSC Primate Specialist Group. S.I.)

ORBAN, B. 1995. An ecological management plan for the Lionspruit Game Reserve. M.Sc (Wildlife Management) Dissertation. University of Pretoria, Pretoria.
Pruetz, J.L. \& L.A. IsBell. 2000. Correlations of food distribution and patch size with agonistic interactions in female vervets (Cercopithecus aethiops pygerythrus senso lato) and patas monkeys (Erythrocebus patas) living in simple habitats. Behavioral Ecology and Sociobiology 49: 38-47.

SkinNeR, J.D. \& R.H.N. SMithers. 1990. The Mammals of the Southern African Subregion. 2nd ed. South Africa: University of Pretoria.

SMit, G.N., C.G.F. Richter \& A.J. Aucamp. 1999. Bush encroachment: An approach to understanding and managing the problem. Pp. 246-260. In: TAINTON R.M. (ed.). Veld management in South Africa. Pietermaritzburg: University of Natal Press.

StRUHSAKER, T.T. 1967. Ecology of Vervet Monkeys (Cercopithecus aethiops). Ecology 48: 891-904.

TUELLER, P.T. 1988. Vegetation science applications for rangeland analysis and management. Dordrecht: Kluwer Academic Publishers.

Tyson, P.D. \& R.A. Preston-Whyte. 2000. The Weather and Climate of Southern Africa. Cape Town: Oxford University Press.

VAN DER SCHIJFF, H.P. 1963. A preliminary account of the vegetation of the Mariepskop Complex. Transvaal Provincial Administration. Fauna and Flora 14: 42-53.

VAN DER SChiJfF, H.P. \& E. SchoonRaAd. 1971. The flora of the Mariepskop Complex. Bothalia 10(3): 461-500.

Van Rooyen, N., G.K. Theron \& N. Grobbelaar. 1981. A floristic description and structural analysis of the plant communities of the Punda Milia-Pafuri-Wambiya area in the Kruger National Park, Republic of South Africa. 1. The hygrophilous communities. South African Journal of Botany 47: 213-246.

VAN ZYL, D. 2003. South African weather and atmospheric phenomena. Pretoria: Briza.

VISSER, D.J.L. (ed.). 1989. The Geology of the Republics of South Africa, Transkei, Bophuthatswana, Venda and Ciskei and the Kingdoms of Lesotho and Swaziland. Geological Survey, Explanation of the 1: 1000000 Geological Map. 4th ed. Pretoria: Government Printer.

Walraven, F. 1989. The Geology of the Pilgrim's Rest Area. Geological Survey, Explanation of Sheet 2430. Pretoria: Government Printer.

WhitTen, P.L. 1988. Effects of patch quality and feeding subgroup size on feeding success in vervet monkeys (Cercopithecus aethiops). Behaviour 105: 35-52. 